\title{
Market Concentration and the Analysis of Vertical Organization
}

\author{
Guanming Shi (Corresponding author) \\ Department of Agricultural and Applied Economics \\ University of Wisconsin, Madison, WI 53706, USA \\ Tel: 1-608-263-6250Ｅ-mail: gshi@wisc.edu \\ Jean-Paul Chavas \\ Department of Agricultural and Applied Economics \\ University of Wisconsin, Madison, WI 53706, USA \\ Tel: 1-608-261-1944Ｅ-mail: jchavas@wisc.edu
}

$\begin{aligned} & \text { Received: December 2, } 2011 \quad \text { Accepted: December 13, } 2011 \quad \text { Published: February 1, } 2012 \\ & \text { doi:10.5539/ijms.v4n1p2ＵRL: http://dx.doi.org/10.5539/ijms.v4n1p2 }\end{aligned}$

\begin{abstract}
This paper proposes concentration indices that extend the classical Hirschman-Herfindahl Index to include vertical structures for differentiated products. The analysis shows how cross-product substitution/complementarity relationships across vertical channels can affect pricing. It also identifies the role played by market size. The usefulness of the approach is illustrated in an application to a merger analysis in the gasoline market.
\end{abstract}

Keywords: Vertical organization, Concentration indices, Differentiated products, Prices

\section{Introduction}

Multi-product companies in today's economy often operate in both horizontal and vertical markets. In this context, understanding the effects of market concentration has been challenging. The Herfindahl-Hirschman Index (HHI) has been used to analyze such effects in horizontal markets (e.g., Whinston, 2006). More recent work has explored the use of concentration indexes in the analysis of the effects of vertical organization on the pricing of homogeneous products (e.g., Gans, 2007; Hendricks and McAfee, 2009). But vertical sectors often involve extensive product differentiation. This suggests a need to refine the economic evaluation of market concentration issues and vertical organization for differentiated products.

The objective of this paper is to investigate the role of market structures for vertically differentiated products. This is done by developing a HHI-type concentration index (termed VHHI for vertical HHI) that applies under vertical product differentiation. The analysis shows how cross-product substitution/complementarity relationships across vertical channels affect pricing. It also identifies the role played by market size. The usefulness of this VHHI approach is illustrated in an analysis of merger in the gasoline market.

\section{Conceptual model}

Consider a vertical sector comprised of $n$ firms that produce $r$ upstream (intermediate) outputs that are used to generate $m$ downstream (final) outputs. Let $\mathbf{y}_{j i}$ denote the vector of intermediate outputs produced by the $j$-th upstream firm and sold to the $i$-th downstream firm. The total quantities of intermediate outputs produced by the $j$-th firm are $\mathbf{y}_{j}^{0}=\sum_{i} \mathbf{y}_{j i}$, while $\mathbf{y}_{i}^{1}=\sum_{j} \mathbf{y}_{j i}$ are the total quantities of intermediate outputs purchased by the $i$-th firm and used to produce final outputs $\mathbf{z}_{i}=\left(z_{i 1}, \ldots, z_{i m}\right) \in \mathbf{R}_{+}^{m}$. The $i$-th firm also purchases other inputs $\mathbf{x}_{i}$ at prices $\mathbf{w}$ under a technology represented by the feasible set $\mathbf{F}_{i}$, where $\left(\mathbf{x}_{i}, \mathbf{y}_{i}^{\mathrm{I}}, \mathbf{y}_{i}^{\mathrm{O}}, \mathbf{z}_{i}\right) \in \mathbf{F}_{i}$ means that inputs $\mathbf{x}_{\mathrm{i}}$ and intermediate outputs $\mathbf{y}_{i}{ }_{i}$ are feasible to produce intermediate outputs $\mathbf{y}_{i}{ }^{\mathrm{O}}$ and final outputs $\mathbf{z}_{i}$.

Let $\mathbf{x}=\left(\mathbf{x}_{1}, \ldots, \mathbf{x}_{n}\right), \mathbf{y}^{\mathrm{O}}=\left(\mathbf{y}_{1}^{\mathrm{O}}, \ldots, \mathbf{y}_{n}^{\mathrm{O}}\right), \mathbf{y}^{\mathrm{I}}=\left(\mathbf{y}_{1}^{\mathrm{I}}, \ldots, \mathbf{y}_{n}^{\mathrm{I}}\right)$ and $\mathbf{z}=\left(\mathbf{z}_{1}, \ldots, \mathbf{z}_{n}\right)$. We assume efficient contracting among the $n$ firms within the vertical sector (Note 1). This means that firms choose inputs $\mathbf{x}$ and intermediate products $\left(\mathbf{y}^{\mathrm{O}}, \mathbf{y}^{\mathrm{I}}\right)$ to minimize aggregate cost:

$$
C(\mathbf{z})=\operatorname{Min}_{\mathbf{x}, \mathbf{y}^{\mathrm{o}}, \mathbf{y}^{\mathrm{I}}}\left\{\mathbf{w} \cdot\left(\sum_{i} \mathbf{x}_{i}\right): \sum_{i} \mathbf{y}_{i}^{\mathrm{O}}=\sum_{i} \mathbf{y}_{i}^{\mathrm{I}} ;\left(\mathbf{x}_{i}, \mathbf{y}_{i}^{\mathrm{I}}, \mathbf{y}_{i}^{\mathrm{O}}, \mathbf{z}_{i}\right) \in \mathbf{F}_{i} ; i=1, \ldots, n\right\},
$$


which has for solution $\mathbf{x}_{\mathbf{i}}^{*}(\mathbf{z}), \mathbf{y}_{i}^{\mathrm{O}^{*}}(\mathbf{z})$ and $\mathbf{y}_{i}^{\mathrm{I}^{*}}(\mathbf{z}), i=1, \ldots, n$. Let $\mathbf{q}^{*}(\mathbf{z})$ denotes the shadow prices of the market-clearing constraint for intermediate outputs: $\sum_{i} \mathbf{y}_{i}^{0}=\sum_{i} \mathbf{y}_{i}^{1}$. For firm $i$, the cost function is:

$$
c_{i}(\mathbf{z})=\mathbf{w} \cdot \mathbf{x}_{i}^{*}(\mathbf{z})+\mathbf{q}^{*}(\mathbf{z}) \cdot\left[\mathbf{y}_{i}^{\mathbf{l}^{*}}(\mathbf{z})-\mathbf{y}_{i}^{\mathrm{O}^{*}}(\mathbf{z})\right],
$$

which satisfies $\quad \sum_{i} c_{i}(\mathbf{z})=C(\mathbf{z})$. Denote final demand by the price dependent demands $\mathbf{p}(\mathbf{Z})=\left(p_{1}(\mathbf{Z}), \ldots, p_{m}(\mathbf{Z})\right)$, where $\mathbf{Z}=\left(Z_{1}, \ldots, Z_{m}\right)=\sum_{i} \mathbf{z}_{i}$ is the vector of aggregate final outputs. The $i$-th firm's profit is:

$$
\pi_{i}=\sum_{k=1}^{m} p_{k}(\mathbf{Z}) \cdot z_{i k}-c_{i}(\mathbf{z}), i=1, \ldots, n .
$$

Under a Cournot game, the optimal choice of $z_{i k}$ satisfies both $\pi_{i} \geq 0$ and the Kuhn-Tucker conditions:

$$
\begin{gathered}
p_{k}(\mathbf{Z})-\partial c_{i} / \partial z_{i k}+\sum_{k^{\prime}=1}^{m} \partial p_{k^{\prime}} / \partial Z_{k} \cdot z_{i k^{\prime}} \leq 0 \\
z_{i k} \geq 0 \\
z_{i k} \cdot\left[p_{k}(\mathbf{Z})-\partial c_{i} / \partial z_{i k}+\sum_{k^{\prime}=1}^{m} \partial p_{k^{\prime}} / \partial Z_{k} \cdot z_{i k^{\prime}}\right]=0
\end{gathered}
$$

Equations $(2 a)-(2 c)$ allow a flexible organization of the vertical sector. It includes firms involved only in upstream markets (when $z_{i k}=0$ for all $k$ ), firms involved only in downstream markets (when $\mathbf{y}_{i}^{\mathrm{o}} \neq 0$ ), and vertically integrated firms involved both upstream and downstream (with $\mathbf{y}_{i}^{\mathrm{o}} \neq 0$ and $z_{i k} \neq 0$ for some $k$ ). Such configurations can be motivated by efficiency gains (when vertical integration contributes to cost reduction) and/or by strategic behavior (e.g., under situations of foreclosure, as discussed by Rey and Tirole (2008)).

Given $Z_{i}>0$, let $s_{i k} \equiv z_{i k} / Z_{k} \in[0,1]$ denote the $i$-th firm's market share for the $k$-th final good. Dividing (2c) by $Z_{k}$ and summing across all firms yield the pricing equation:

$$
p_{k}(\mathbf{Z})-\sum_{i} s_{i k} \cdot \partial c_{i} / \partial z_{i k}=-\sum_{k^{\prime}=1}^{m} \partial p_{k^{\prime}} / \partial Z_{k} \cdot H_{k k^{\prime}} \cdot Z_{k^{\prime}}
$$

where $H_{k k^{\prime}} \equiv \sum_{i} s_{i k} \cdot s_{i k^{\prime}} \in[0,1]$. The term $M_{k} \equiv-\sum_{k^{\prime}=1}^{m} \partial p_{k^{\prime}} / \partial Z_{k} \cdot H_{k k^{\prime}} \cdot Z_{k^{\prime}}$ in (3) is a markup measuring the departure from marginal cost pricing for the $k$-th final good. The term $\partial p_{k^{\prime}} / \partial Z_{k}$ captures both own-price effect (when $k^{\prime}=k$ ) and cross-price effects (when $k^{\prime} \neq k$ ). Under constant marginal cost, $M_{k} / p_{k}$ is the Lerner Index in the $k$-th market.

In general, $M_{k}$ establishes linkages between pricing and market concentrations (as measured by $H_{k k^{\prime}}$ ). When $k=k^{\prime}, H_{k k} \equiv \sum_{i} s_{i k}^{2}$ reduces to the classical Hirschman-Herfindahl Index (HHI) of concentration in the $k$-th submarket. When demands are downward sloping (with $\partial p_{k} / \partial Z_{k}<0$ ), this yields the standard result that an increase in $H_{k k}$ (reflecting increased concentration) contributes to a higher markup in the $k$-th submarket.

When $k \neq k^{\prime}, \quad H_{k k^{\prime}} \equiv \sum_{i} s_{i k} \cdot s_{i k^{\prime}}$ is a cross-market concentration index. From (3), any increase in $H_{k k^{\prime}}$ contributes to a higher (lower) markup $M_{k}$ and Lerner Index $M_{k} / p_{k}$ when $\partial p_{k} / \partial Z_{k}<0(>0)$. Define goods $k$ and $k^{\prime}$ to be substitutes (complements) when increases in $Z_{k}$ reduce (stimulate) consumers' willingness-to-pay for good $k^{\prime}$ (Hicks, 1939). This implies that an increase in cross-market concentration $H_{k k^{\prime}}$ contributes to higher markup $M_{k}$ when final goods $k$ and $k^{\prime}$ are substitutes, and to a lower markup $M_{k}$ when they are complements. When final goods $k$ and $k^{\prime}$ are differentiated by the corresponding vertical channels, the $H_{k k^{\prime}}$ s become measurements of vertical market concentration and are then termed as "vertical HHI" or VHHI.

What if final products are perfect substitutes? If so, the law of one price applies (with $p_{k}(\mathbf{Z})=p(\mathbf{Z})$ ), and the price-dependent demand takes the form $p(\mathbf{Z})=p(Z)$, where $Z=\sum_{k} Z_{k}=\sum_{k} \sum_{i} z_{i k}$. Let $S_{i}=\sum_{k} z_{i k} / Z$ denote firm $i$ 's aggregate market share. Then multiplying $M_{k}$ by $Z_{k} / Z$ and summing over $k$ yield:

$$
\begin{aligned}
M \equiv \sum_{k} Z_{k} / Z \cdot M_{k}=-\sum_{k}\left\{Z_{k} / Z \cdot \sum_{k} \cdot\left[\partial p / \partial Z \cdot \sum_{i}\left(z_{i k} / Z_{k} \cdot z_{i k^{\prime}} / Z_{k^{\prime}}\right) \cdot Z_{k^{\prime}}\right]\right\} \\
\quad=-\partial p / \partial Z \cdot \sum_{i} \sum_{k} \sum_{k^{\prime}}\left(z_{i k} / Z \cdot z_{i k^{\prime}} / Z\right) \cdot Z \\
\quad=-\partial p / \partial Z \cdot H H I \cdot Z,
\end{aligned}
$$

where $H H I \equiv \sum_{i} S_{i}^{2}$ is the classical Hirschman-Herfindahl Index evaluated at the aggregate level. Equation (4) defines the markup $M$ as a weighted average of the $M_{k}$ 's across all final goods. Then, (4) shows that, under perfect substitution, market power can be analyzed as if there is a single market. In this particular case, the markup $M$ is then proportional to the classical HHI. Additionally, $H H I=\sum_{k} \sum_{k^{\prime}} Z_{k} / Z \cdot Z_{k^{\prime}} / Z \cdot H_{k k^{\prime}}$, showing that the classical HHI is a weighted average of the $H_{k k^{\prime}} \mathrm{s}$, with market shares as weights. Finally, comparing the markups $M$ and $M_{k}$ indicates how differentiated products impact the evaluation of market concentration effects. This shows that, by allowing departures from perfect substitution, our approach extends the use of HHI indexes to the investigation of markets for differentiated products. When applied to vertically differentiated products, this extends the analysis presented by Gans (2007) (who assumes a homogeneous product). As such, the VHHI's in Equation (3) provide a broad basis to investigate the effects of vertical structures on pricing. 
Equation (3) also shows how market concentration interacts with market size $Z_{k^{\prime}}$. Indeed, the price effect of cross-market concentration is present only when $Z_{k^{\prime}}$ is positive; and it is likely important only when the market size, $Z_{k^{\prime}}$, is sufficiently large. It means that such interaction effects are relevant only in the absence of foreclosure. These effects are exemplified next in the analysis of a merger.

\section{An application: merger in the gasoline market}

This section illustrates the usefulness of our approach through an analysis of mergers involving vertically differentiated products. Like Gans (2007) and Hendricks and McAfee (2009), we use the example of Exxon-Mobil merger and the California gasoline market (Note 2). We evaluate how alternative mergers impact retail gasoline prices (Note 3), and compare our VHHI approach with the classical HHI and with Gans' approach (Gans, 2007).

Both Gans (2007) and the classical HHI implicitly assume perfect substitutes in final goods. In contrast, we treat gasoline as differentiated goods across vertical channels. This is supported by Hastings' (2004) analysis of the gasoline market in southern California that consumers view branded gasoline as different from independently-sold gasoline. The branded gasoline is produced and marketed by vertically integrated channel (denoted by $v$ ), while the independent stations sell gasoline through non-integrated channel (denoted by $u$ ). One of our key points is the need to take into consideration the fact that consumers see gasoline produced under vertical integration $(v)$ as differentiated from gasoline produced under non-integration $(u)$.

For the purpose of comparison, we follow Gans (2007) who makes the following assumptions (Note 4): the downstream production technology is Leontief, and vertically integrated firms always use their own refinery petroleum (upstream output) first. We label alternative concentration measures as follows: Classical HHI, Gans' proposed vertical indices under contracting (hereafter termed Gans-VHHI, defined as $\sum_{i}\left[s_{i} \cdot \max \left(s_{i}, \sigma_{i}\right)\right]$, where $s_{i}$ and $\sigma_{i}$ are respectively the downstream and upstream market shares of the $i$-th firm), and our VHHI. Table 1 presents these measures. In contrast to the single measure of the classical HHI or Gans-VHHI, our VHHI contains three measures: Two encapsulates the within-market concentration for both channels $\left(\mathrm{VHHI}_{u}\right.$ for the non-integrated channel and $V H H I_{v v}$ for the integrated channel), and a third denotes the cross-market concentrations ( $V H H I_{u v}$ across channels).

The Exxon-Mobil merger unambiguously increases concentration measures under all three approaches: $11 \%$ for the classical HHI, $9.7 \%$ for the Gans-VHHI, and $18.1 \%$ for $V H H I_{u u}, 7.8 \%$ for $V H H I_{v v}$, and $24.6 \%$ for $V H H I_{u v}$. Our VHHI details how the merger affects the within- and cross-market concentrations, therefore provides important information in evaluating alternative merger scenarios.

Our method distinguishes between mergers without divestiture and those with upstream or downstream divestiture. This is in sharp contrast with the classical HHI. Indeed, the classical HHI does not account for upstream divestiture when evaluating a post-merger downstream situation. Furthermore, with the classical HHI, a downstream divestiture eliminates a merger's impact on the downstream market completely. The Gans-VHHI is similar to the classical HHI: the upstream divestiture does not change the post-merger downstream Gans-VHHI.

Our VHHI, however, shows that with upstream divestiture, the two within-market concentration measures $\left(V H H I_{v v}\right.$ and $\left.V H H I_{u u}\right)$ increase, and the cross-market concentration measure $\left(V H H I_{u v}\right)$ decreases. When downstream divestiture occurs, within-market concentration measures also increase in relation to those for non-divestiture mergers, but these increases are smaller than those in the upstream divestiture scenarios. Similar results hold for the cross-market concentration measures.

We computed and compare the simulated markups $M$ and Lerner Indices (expressed in percentage term as $100 \cdot M / p$ ) generated by the three different approaches under alternative merger/divestiture scenarios (see table 2). The pattern of changes in markups and Lerner Indices for the classical HHI and Gans-VHHI is similar to that of table 1. This reflects the fact that both approaches assume that the demand coefficient and market size variables remain constant before and after a merger, regardless of the divestiture requirements. Thus, only the concentration measures change. Conversely, with our VHHI approach, divestiture requirements also impact market sizes $Z_{u}$ and $Z_{v}$. It shows that the overall effects of divestiture reflect both changes in VHHIs and changes in market size. Because of the market size effects, our estimated markups and Lerner Indices are significantly lower for the non-integrated market than for the vertically integrated market. Moreover, all of our markup estimates are much lower than those generated by the classical HHI and Gans-VHHI (see table 2). This illustrates the importance of capturing the role of market size in the evaluation of changes in vertical organization. Since our proposed measure incorporates such effects (while the classical HHI and Gans-VHHI do not), this is a useful and distinctive characteristic of our approach. 
Finally, neither the classical HHI nor the Gans-VHHI captures any of the impacts of an upstream divestiture merger policy. Our VHHI approach, however, suggests that under merger with upstream divestiture, markups and Lerner Indices for the vertically integrated gasoline market decrease slightly (from $\$ 0.73$ to $\$ 0.72$, and from 49.2 to 48.5 ), and those for the non-integrated market rise modestly (from $\$ 0.47$ to $\$ 0.57$, and from 33.2 to 40.3 ).

This example demonstrates the usefulness of our VHHI concentration indices in analyzing the impacts of different merger/divestiture policies. Our approach captures both within- and cross-market concentration effects in a vertical sector, and accounts for the changes in market size that are associated with different merger/divestiture scenarios (Note 5). Finally, our approach is empirically tractable, and offers economists and scholars a refined way to analyze the effects of market power and vertical organization on pricing.

\section{Conclusion}

Our paper has investigated how vertical firms price differentiated products. We have developed a Cournot model that captures how vertical organization impacts differentiated product pricing under imperfect competition. Our analysis proposes concentration indices that extend the classical HHI to include vertical structures under differentiated products. We also discuss limitations in the concentration indices proposed by Gans (2007).

Our approach illustrates how cross-product substitution/complementarity relationships across vertical channels affect pricing. We also identify the ways in which market size interacts with market concentration and cross-product relationships.

The usefulness of the approach is illustrated in an application to mergers in the gasoline market. The application showed how our VHHIs capture the impacts of different merger/divestiture policies. Importantly, neither the classical HHI nor Gans-VHHI can catch such impacts. As such, our approach provides new insights on the effects on changing market structures on pricing in vertical sectors. And it can help inform the design and evaluation of antitrust policy.

\section{References}

Gans, J.S. (2007). Concentration-Based Tests and Vertical Market Structure. Journal of Law and Economics, 50, 661-680. http://dx.doi.org/10.1086/519819

Hastings, J.S. (2004). Vertical Relationships and Competition in Retail Gasoline Markets: Empirical Evidence from Contract Changes in Southern California. The American Economic Review, 94(1), 317-328. http://dx.doi.org/10.1257/000282804322970823

Hicks, JR. (1939). Value and Capital: An Inquiry into some Fundamental Principles of Economic Theory. Clarendon Press. Oxford.

Hendricks, K., and R.P. McAfee. (2009). A Theory of Bilateral Oligopoly. Economic Inquiry, 48(2), 391-414. http://dx.doi.org/10.1111/j.1465-7295.2009.00241.x

Rey, P., and J. Tirole. (2008). A Primer on Foreclosure. Handbook of Industrial Organization, Vol III. Mark Armstrong and Robert Porter, Editors, North Holland, Amsterdam.

Salinger, M.A. (1988). Vertical Mergers and Market Foreclosure. Quarterly Journal of Economics, 103, 345-356. http://dx.doi.org/10.2307/1885117

Shi, G., and J.P. Chavas. The Effects of Vertical Organization on the Pricing of Differentiated Products. Journal of Agricultural and Resource Economics, in press.

Shi, G., K. Stiegert and J.P. Chavas. (2011). An Analysis of Bundle Pricing in Horizontal and Vertical Markets: The Case of the U.S. Cottonseed Market. Agricultural Economics, 42, 77-88. http://dx.doi.org/10.1111/j.1574-0862.2011.00553.x

Whinston, M.D. (2006). Lectures on Antitrust Economics. MIT Press, Cambridge, MA.

\section{Notes:}

Note 1. This ignores issues of double marginalization. While such issues may be of interest, they are beyond the scope of this paper.

Note 2. Other applications of our VHHI approach to the analysis of vertical organization can be found in Shi and Chavas (in press) for an application to the soybean seed market, and Shi et al. (2011) for an application to the cotton seed market.

Note 3. Data on market shares for petroleum refining and gasoline retailing are taken from Gans (2007, table 1, p.673). 
Note 4. These assumptions are for illustrative purposes.

Note 5. As discussed above, our approach also captures complementarity/substitution effects through cross-market effects.

Table 1. Concentration measures

\begin{tabular}{|c|c|c|c|c|c|}
\hline \multicolumn{2}{|c|}{ Concentration Measure } & Pre-merger & Post-merger & $\begin{array}{c}\text { Post-merger } \\
\text { with Exxon } \\
\text { Refinery } \\
\text { Divestiture }\end{array}$ & $\begin{array}{c}\text { Post-merger } \\
\text { with Exxon } \\
\text { Retail } \\
\text { Divestiture } \\
\end{array}$ \\
\hline \multicolumn{2}{|c|}{ Upstream HHI } & 0.1758 & 0.1856 & 0.1758 & 0.1856 \\
\hline \multicolumn{2}{|c|}{ Downstream HHI } & 0.1577 & 0.1750 & 0.1750 & 0.1577 \\
\hline \multicolumn{2}{|l|}{ Gans-VHHI } & 0.1791 & 0.1964 & 0.1964 & 0.1833 \\
\hline \multirow[t]{3}{*}{ Our VHHIs } & $V H H I_{u u}$ & 0.2975 & 0.3514 & 0.4168 & 0.3815 \\
\hline & $V H H I_{v v}$ & 0.1694 & 0.1826 & 0.1929 & 0.1871 \\
\hline & $V H H I_{u v}$ & 0.1100 & 0.1371 & 0.1092 & 0.0665 \\
\hline
\end{tabular}

Note: All measures are based on summing the relevant shares under different merger scenarios. See Gans (2007, table 2, p.674) for Gans-VHHI.

Table 2. Simulated impact of merger

\begin{tabular}{|c|c|c|c|c|}
\hline & Pre-merger & Post-merger & $\begin{array}{c}\text { Post-merger } \\
\text { with Exxon } \\
\text { Refinery } \\
\text { Divestiture }\end{array}$ & $\begin{array}{c}\text { Post-merger } \\
\text { with Exxon } \\
\text { Retail } \\
\text { Divestiture }\end{array}$ \\
\hline \multicolumn{5}{|c|}{ Perfect Substitutes: Classical HHI } \\
\hline$M$, Price Markup (\$) & 0.69 & 0.77 & 0.77 & 0.69 \\
\hline $100 \cdot M / p$, Lerner Index & 47.6 & 53.1 & 53.1 & 47.6 \\
\hline \multicolumn{5}{|c|}{$\begin{array}{l}\text { Formula: } M=-\partial p / \partial Z \cdot H \cdot Z, \text { where } H \equiv \text { classical } H H I \\
\text { Parameter Values: } \partial p / \partial Z=-0.44, \quad Z=Z_{u}+Z_{v}=10, \quad p=\$ 1.45\end{array}$} \\
\hline \multicolumn{5}{|c|}{ Perfect Substitutes: Gans-VHHI } \\
\hline$M$, Price Markup (\$) & 0.79 & 0.86 & 0.86 & 0.81 \\
\hline $100 \cdot M / p$, Lerner Index & 54.5 & 59.3 & 59.3 & 55.9 \\
\hline \multicolumn{5}{|c|}{$\begin{array}{l}\text { Formula: } M=-\partial p / \partial Z \cdot H \cdot Z \text {, where } H \equiv \text { Gans' VHHI } \\
\text { Parameter Values: } \partial P / \partial Z=-0.44, \quad Z=Z_{u}+Z_{v}=10, \quad p=\$ 1.45\end{array}$} \\
\hline \multicolumn{5}{|c|}{ Differentiated Products Across Vertical Channels: our VHHI } \\
\hline$M_{u}$, Price Markup $(\$)$ & 0.39 & 0.47 & 0.57 & 0.42 \\
\hline $100 \cdot M_{u} / p_{u}$, Lerner Index & 27.6 & 33.2 & 40.3 & 29.7 \\
\hline$M_{v}$, Price Markup (\$) & 0.68 & 0.73 & 0.72 & 0.70 \\
\hline $100 \cdot M_{v} / p_{v}$, Lerner Index & 45.8 & 49.2 & 48.5 & 47.1 \\
\hline
\end{tabular}

Note: Demand coefficients and prices are derived from Hastings (2004) and Hendricks and McAfee (2009). Market size $Z$ is set equal to 10 . 